\title{
Las potencialidades del uso del lenguaje positivo en el proceso de enseñanza-aprendizaje
}

\author{
Juan José Salvado Ortega \\ Profesor del Departamento de Ciencias de la Educación y codirector del \\ Máster en Formación del Profesorado de Educación Secundaria y Bachillerato, \\ Formación Profesional y Enseñanza de Idiomas de la Universidad Rey Juan Carlos \\ juanjose.salvado@urjc.es
}

Este trabajo ha sido seleccionado para su publicación por: doña Elena Faba de la Encarnación, doña Charo Fernández Aguirre, don Melchor Gómez García, doña Laura Rayón Rumayor y don Javier Soriano Camino.

\section{Extracto}

El empleo de un lenguaje positivo por parte del docente produce unos efectos emocionales que generan en los individuos unos pensamientos y comportamientos óptimos para el aprendizaje. Una comunicación positiva eleva los niveles atencionales, memorísticos, motivacionales y creativos, y, por ende, beneficia las dinámicas académicas, produciendo una mejora en el rendimiento de los alumnos. En el presente artículo se comienza con una revisión bibliográfica de las claves teóricas de la neuroeducación, elemento clave para establecer los mecanismos básicos del aprendizaje cerebral, para, a posteriori, estudiar su implicación y aplicación en el ámbito educativo. Análogamente, se revisan las emociones y el lenguaje, finalizando con una reflexión acerca del papel del profesor y su capacidad potencial a través del lenguaje para mejorar el proceso de enseñanza y aprendizaje.

Palabras clave: lenguaje positivo; neurodidáctica; emociones; enseñanza y aprendizaje. enseñanza-aprendizaje. Tecnología, Ciencia y Educación, 15, 81-103. 


\title{
The potentialities of using positive language in the teaching-learning process
}

\author{
Juan José Salvado Ortega
}

\section{Abstract}

The use of positive language by a teacher produces emotional effects that generate optimal thoughts and behaviors for learning. A positive communication in the teaching and learning process is able to improve attentional, memoristic, motivational and creative levels, and therefore, the academic dynamics produces an improvement in the academic performance of students. This article begins with a bibliographic review of the theoretical keys of neuroeducation, a key element to establish the basic mechanisms of brain learning, to subsequently study its involvement and application in the educational field. Similarly, emotions and language are reviewed, ending with a reflection on the teacher's role and potential capacity through language to improve the teaching and learning process.

Keywords: positive language; neurodidactic; emotions; teaching and learning.

Citation: Salvado Ortega, J. J. (2020). The potentialities of using positive language in the teaching-learning process. Tecnología, Ciencia y Educación, 15, 81-103. 


\section{Sumario}

1. Introducción

2. Objetivos

3. Neurociencia y cerebro

3.1. Neuroeducación y enseñanza-aprendizaje

3.2. Las emociones y su papel en el aprendizaje

3.3. Relación entre emociones, memoria y atención

3.4. La relación entre emoción y motivación

4. Lenguaje

4.1. Análisis de la alteración que el lenguaje ejerce sobre el cerebro

4.2. La influencia del lenguaje en nuestro comportamiento

5. El lenguaje positivo

5.1. El lenguaje positivo en la enseñanza

5.2. El papel del profesor

5.3. La influencia del lenguaje positivo en los alumnos

5.4. A la búsqueda de metodologías apropiadas

6. Conclusiones

Referencias bibliográficas

Nota: este artículo es un extracto del trabajo fin de máster (TFM) elaborado por el autor como parte de los estudios del Máster Universitario en Competencias Docentes Avanzadas para Niveles de Infantil, Primaria y Secundaria, impartido en la Universidad Rey Juan Carlos durante el curso académico 2017/2018. La dirección del TFM ha sido llevada a cabo por Raquel Garrido Abia, profesora y directora del citado máster. 


\section{Introducción}

Hoy en día es recurrente oír y leer a través de los medios de comunicación numerosas recomendaciones sobre cómo mejorar nuestra salud, vivir más años o llevar una vida lo más sana posible. Para ello, comer sano, pasar tiempo con amigos, realizar ejercicio moderado, respetar unas horas de sueño, entre muchos otros hábitos, suelen ser los consejos más habituales que recibimos. En cambio, el número de informaciones que hacen referencia al lenguaje y a la educación lingüística en este aspecto es realmente escaso. Y todavía son más inusuales las informaciones sobre cómo mejorar el rendimiento cognitivo a través de las palabras, de las palabras positivas (Castellanos, 2017).

La educación se considera de una importancia capital para las sociedades actuales; por ello, se establece como una de las premisas que más preocupan, por su alta influencia en las perspectivas sociales y personales de los seres humanos (Delval, 1996). La educación tiene el deber de «proporcionar las cartas náuticas de un mundo complejo y en perpetua agitación y, al mismo tiempo, la brújula para poder navegar por él» (Delors, 1996, p. 96).

En ello, el docente se configura como eje central y coordinador de toda la red de relaciones interpersonales y dinámicas que se puedan dar en la comunidad educativa. Por ende, es indispensable una reflexión sobre el impacto de las estrategias pedagógicas que se utilizan (Guillén, 2016), más aún cuando el porcentaje de la tasa de abandono escolar en España alcanza el $18,3 \%$, una media superior a la de la Unión Europea (Fundación BBVA, 2018).

En este último lustro, especialmente, el acto educativo está siendo fuertemente influenciado por los hallazgos de la neurociencia, más concretamente de la neuroeducación o neurodidáctica,

El docente se configura como eje central y coordinador de toda la red de relaciones interpersonales y dinámicas que se puedan dar en la comunidad educativa llegando incluso a revolucionar en muchas vertientes el proceso de enseñanza-aprendizaje (Marina, 2012; Ferrés, 2014). Tras sus hallazgos sobre cómo aprende el cerebro, manifiesta la necesidad de incluir la emoción en el proceso educacional (Guillén, 2016). Todo aprendizaje debe poseer una experiencia afectiva, ya que emoción y cognición son procesos que van de la mano (Damasio, 1994). Como plantea Ferrés (2014), arduamente se puede adquirir 
un conocimiento si no subyace la motivación o si el contenido no goza de un significado que provoque atención. $Y$ es que el papel evolutivo que tienen las emociones en nuestro proceso cognitivo es un elemento indispensable, aunque a veces ni siquiera nos demos cuenta (Forés y Ligioiz, 2009).

Como reflexiona Ferrés (1994), el acto de enseñar no es un acto meramente informativo, sino que debe valerse de un lenguaje persuasivo. Los docentes tienen, a través de sus métodos, el poder seductor para encender en los discentes el deseo por la educación, produciendo una eficacia y una experiencia rica con resultados perdurables.

Vygotsky (1988) ya afirmaba que conversación y acción son parte de una misma función psicológica, siendo el lenguaje el predecesor de las acciones. Echeverría (2003) plantea que el lenguaje que postulamos es crucial para entender los fenómenos humanos. Morín (1992) asegura que el lenguaje se suspende de las interacciones entre individuos, los cuales, a su vez, dependen del lenguaje, ofreciendo en el acto comunicativo una carga simbólica positiva o negativa, siendo ello aprehendido y adoptado de unos a otros.

En vista de ello, Zambrano (2001) señala que la acción comunicativa de los docentes juega un papel determinante en el éxito o en el fracaso escolar: «Es necesario que el docente comprenda que una mirada puede garantizar el triunfo o la condena infinita del otro» (p. 47).

La acción comunicativa de los docentes juega un papel determinante en el éxito o en el fracaso escolar Para Castellanos (2017), «las palabras son vehículos físicos de las emociones» (p. 40). En función de si la emoción es positiva o negativa, esta puede cambiar el estado de activación de nuestro cerebro de una manera sustancial y, por ende, de nuestro comportamiento.

En 1977, Bandura ya planteaba que el resultado de una conducta se producía por las creencias y valoraciones que uno mismo hace de sus capacidades; es decir, las expectativas que generamos en nuestros alumnos repercutirán en su motivación de rendimiento.

Las expectativas que generamos en nuestros alumnos repercutirán en su motivación de rendimiento

Es más, se afirmaba una relación directa entre el desarrollo de la autoestima de un alumno y su rendimiento académico. En este mismo sentido, Cabrera (2003) ratifica que «los alumnos responden positivamente o negativamente a la participación en forma directamente proporcional, según sea el mensaje y la actitud del profesor» (p. 6), induciendo a pensar que la comunicación verbal y gestual del docente son unas variables determinantes en el éxito del proceso educativo.

Varios estudios -como los de Echeverría (2003), Greco, Morelato e Ison (2006) o Seligman, Ernst, Gillham, Reivich y Linkins (2009)- muestran que experimentar emociones positivas favorece la atención, la motivación y el pensamiento creativo, promueve la flexibilidad 
cognitiva y aumenta los recursos intelectuales, contrarrestando las tendencias negativas. Asimismo, estudios tales como el de Westling (2002) o el de Sutton y Wheatly (2003) manifiestan que la sensación de emociones positivas genera un clima de aula óptimo para el aprendizaje e incluso para disminuir conductas desadaptativas.
Experimentar emociones positivas favorece la atención, la motivación y el pensamiento creativo, promueve la flexibilidad cognitiva y aumenta los recursos intelectuales

Por todo lo citado anteriormente, surge el interés de esta investigación. En primer lugar, para identificar y analizar el protagónico papel que desempeña el lenguaje de los docentes; en segundo lugar, para conocer las potencialidades del lenguaje positivo en el proceso de enseñanza-aprendizaje; y, finalmente, para poder reflexionar así sobre las maneras en las que el docente se relaciona con el estudiante.

\section{Objetivos}

Objetivo principal:

- OP1. Determinar si el lenguaje positivo mejora el proceso de enseñanza-aprendizaje y, consecuentemente, el rendimiento académico de los educandos.

Objetivos específicos:

- OE1. Analizar la influencia del lenguaje positivo en las emociones y, por ende, sus efectos en el proceso educativo de los educandos.

- OE2. Reflexionar sobre el papel que desempeña el lenguaje en la manera que tienen los docentes de comunicarse con sus discentes.

\section{Neurociencia y cerebro}

El estudio del estado de la cuestión de esta investigación se articula mediante la siguiente frase de Leslie Hart: «Educar sin saber cómo funciona el cerebro es como querer diseñar un guante sin haber visto nunca una mano» (citado en Ibarrola, 2016, p. 15).

Por ese motivo, la neurociencia está conformándose como una de las ramas del saber científico que más está madurando y creciendo en los últimos años, produciéndose un notable aumento en sus investigaciones y aplicaciones. 
Lo que la neurociencia va ratificando en sus continuos progresos es que el cerebro posee una gran plasticidad, siendo esto una de las bases de los procesos de la memoria y el aprendizaje. Precisamente por esta razón, el cerebro puede aprender y adaptarse a las miles de situaciones y experiencias que le suceden. Para que las conexiones neuronales se produzcan en mayor medida y de una manera sólida, los estímulos emocionales juegan un papel crucial, ya que son capaces de cambiar el estado de activación de nuestro cerebro, engranar un mejor funcionamiento de nuestros procesos mentales y cognitivos y estimular los mecanismos sensoriales y motores a nivel cardiovascular y respiratorio; incluso llegan a producir cambios a nivel hormonal y metabólico que adecuan nuestro organismo a cualquier circunstancia de cara a poder dar respuestas efectivas (Forés y Ligioiz, 2009).

Estos hallazgos que la neurociencia manifiesta están produciendo cambios notables en numerosos preceptos, tales como la salud o la enseñanza. El neurocientífico Manfred Spitzer ha llegado incluso a afirmar que «la neurociencia será a la educación lo que la biología ha sido a la medicina» (Forés et al., 2015, p. 14).

\subsection{Neuroeducación y enseñanza-aprendizaje}

Tradicionalmente, la cultura occidental había concebido lo emocional como un impedimento para el desarrollo pleno de las capacidades intelectuales del ser humano, es decir, la razón fue entronizada en detrimento de la emoción (Ferrés, 2014). Damasio, en su libro El error de Descartes (1994), expuso, ante la incredulidad de muchos, que las emociones podían irrumpir en la espiral de la razón suponiendo un aporte beneficioso en el proceso de razonamiento. Años más tarde Damasio (2001) enuncia que «la participación obligada de las emociones en el proceso de razonamiento puede resultar ventajosa o perniciosa según las circunstancias de la decisión y el pasado del que decide» (p. 4).

Mora (2013) afirma que solo se puede aprender aquello que se ama, induciendo a la idea de que lo emocional es imprescindible para que resulte un eficaz proceso de aprendizaje y memoria. Maturana (2009) plantea en esta misma línea que «todas las acciones humanas se fundan en lo emocional», añadiendo que «el razonar también, pues todo sistema racional tiene fundamento emocional» (p. 23). Por tanto, las emociones sirven de guía para una eficaz toma de decisiones. Es lo que uno ama y le seduce por lo que el ser humano se mueve (Ferrés, 2014). De este modo, a través de la neurociencia, la emoción adquiere un papel protagonista; por supuesto, sin dejar a un lado la razón, ya que nos ofrece la oportunidad de pensar con inteligencia previamente a reaccionar de forma inteligente (Damasio, 2001). En definitiva, razón y emoción deben ser aunadas y entendidas en una relación mutua de dependencia y reciprocidad.

\section{Razón y emoción deben ser aunadas y entendidas en una relación mutua de dependencia y reciprocidad}


El estudio del cerebro ha modificado con su rápido desarrollo la forma de abordar la enseñanza, entendiendo el proceso de aprendizaje como un proceso neuronal que se produce a lo largo de toda la vida del individuo. El cerebro aprende de manera automática, a través de estímulos de los que el sujeto, en la gran mayoría de los casos, no es ni siquiera consciente (Böttger, 2016).

El cerebro es la sede del aprendizaje. Los estudios cada vez más determinantes sobre los efectos de los estímulos emocionales permiten a los docentes reflexionar sobre la importancia de incluir las emociones y las relaciones de apego con sus estudiantes. Su inclusión en los procesos educacionales produce un alumnado motivado que aprende mejor (Ibarrola, 2016).

Forés y Ligioiz (2009) afirman que «la fuente de nuestro deseo por aprender radica en nuestras emociones; eso [...] los publicistas hace años que lo han descubierto; el cerebro emocional tiene la clave para fomentar estas ganas por saber» (p. 25). Es crucial que se cree un ámbito donde los estudiantes sesientan emocionalmente bien y puedan desarrollarse con éxito, y donde la calidad de la relación interpersonal sea la llave maestra para erigir este ambiente de aprendizaje compatible con el cerebro.

Para ello, el lenguaje y las palabras, en particular, poseen una carga emocional que transfiere estados de ánimo a la persona que tenemos en frente. Consecuentemente

\section{El lenguaje y las palabras, en particular, poseen una carga emocional} a la exposición continua de ideas y/o conceptos positivos, el procesamiento neuronal se optimiza al activar e implicar una red más extensa de neuronas ante estímulos emocionales positivos. Dichas respuestas se reflejan en nuestra manera de pensar, de reflexionar o de planificar, así como también en nuestro cuerpo, en forma de marcadores somáticos (Damasio, 2005).

\subsection{Las emociones y su papel en el aprendizaje}

En el Diccionario de neurociencias, de Mora y Sanguinetti (2004), la emoción es definida como «una reacción conductual subjetiva producida por la información proveniente del mundo externo o interno del individuo» (citado en Ibarrola, 2016 p. 138). Como dice el doctor Sylvester, «las emociones manejan la atención, que maneja el aprendizaje, la memoria y casi todo lo demás» (citado en Ibarrola, 2016,

Las emociones manejan la atención, que potencia el aprendizaje, la memoria y casi todo lo demás p. 168), y, según McEwen y Sapolsky (1995), nos aprovisionan de un cerebro químicamente estimulado, es decir, un cerebro más activado que tiene como resultado recordar mejor las cosas. 
Asimismo, la emoción y la motivación orquestan el sistema atencional, el cual decide y selecciona aquellas informaciones que se aprenden. Por el contrario, ante situaciones de adversidad o sobrecarga de tensión, el cerebro segrega las llamadas «hormonas del estrés», como la noradrenalina y el cortisol, que influyen en los procesos de consolidación de la memoria y bloquean la corteza prefrontal.

Para Lautrey, «los fracasos escolares masivos se deben con frecuencia a factores afectivos, emocionales o relacionales, frente a los cuales el análisis de los procesos cognitivos equivale a la realización de un bordado inglés en una tela de arpillera» (citado en Ibarrola, 2016, p. 175).

\subsection{Relación entre emociones, memoria y atención}

De acuerdo con Mayer (2003), «el aprendizaje es la construcción del conocimiento; la memoria es el almacenamiento y el pensamiento es la manipulación lógica de ese conocimiento» (citado en Ibarrola, 2016, p. 223). Emoción y memoria son procesos que están íntimamente conectados. La información que se recibe será potencialmente más significativa cuanto más peso tengan las emociones en la cognición. Las experiencias que implican estímulos cargados de emoción son más fácilmente memorizadas, y dicha información es frecuentemente más utilizada que aquella que no posee codificación emocional (Ibarrola, 2016). Ello se debe a que cuando el cerebro detecta un acontecimiento cargado emocionalmente, la amígdala segrega dopamina. Esta hormona potencia las conexiones neuronales y ayuda, por ende, a la memoria y al procesamiento de información. Se puede afirmar que un factor determinante para la consolidación de los recuerdos es el clima emocional vivido cuando se adquiere dicha información (lbarrola, 2016).

\section{Emoción y memoria son procesos que están íntimamente conectados}

En lo referente a la atención y a la emoción, conseguir la primera en los alumnos ha sido y sigue siendo el gran reto y objetivo de los docentes. Para su consecución, las emociones positivas, de la mano de nuevos y atractivos contenidos, se posicionan como firmes aliadas para la captación de dicha atención. Resulta fundamental transmitir fascinación y curiosidad a los alumnos, ya que «activa los circuitos emocionales del cerebro que nos permiten estar atentos», facilitando así las dinámicas educativas (Forés et al., 2015, p. 50).

Mora (2013) define la atención «como una ventana que se abre en el cerebro a través de la cual se aprende y se memoriza la información que procede del mundo que nos rodea». María Montessori, entre otros ilustres pedagogos, han destacado desde hace casi un siglo, precisamente, el relevante desempeño del asombro en el aprendizaje y su relación con la atención (L'Ecuyer, 2012). 
Forés et al. (2015) afirman que «lo novedoso, la incertidumbre, la curiosidad y la expectación aumentan los niveles de dopamina, lo que favorece la atención y el interés" (p. 117). Son el estado de ánimo, el humor y las emociones los que dictan sobre la atención (Ibarrola, 2016).

Es imprescindible, por tanto, concebir emoción, atención y memoria como tres aspectos de la cognición en permanente y recíproca interacción. Las emociones producen ese interés y mantienen esa curiosidad que resulta crucial para almacenar y

\section{Es imprescindible, por tanto, concebir emoción, atención y memoria como tres aspectos de la cognición en permanente y recíproca interacción} buscar recuerdos de una manera más efectiva. Los componentes químicos que nutren las emociones positivas en nuestro cerebro funcionan como una savia vital en el sistema atencional (Ibarrola, 2016).

Una vez presentado el desafío, el hemisferio izquierdo verbal y lógico del alumno se activa, produciendo dopamina. Durante el proceso de resolución del desafío existe una elevada actividad cerebral y se produce adrenalina. Y, finalmente, una vez el alumno ha descubierto la solución, surge una gran satisfacción y el cerebro libera serotonina (véase figura 1).

Figura 1. Segregación de distintas sustancias cerebrales en función de la actividad

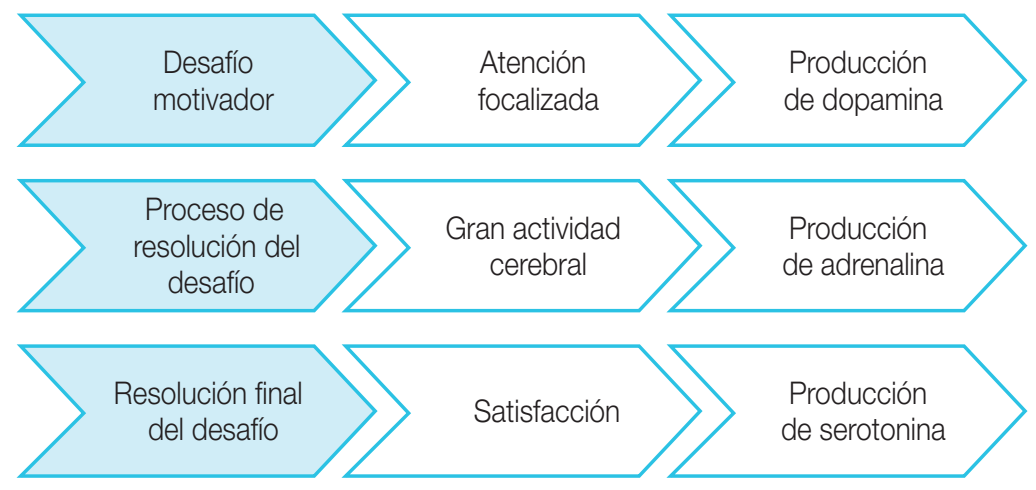

Fuente: elaboración propia a partir de lbarrola (2016, p. 248). 


\subsection{La relación entre emoción y motivación}

La motivación es la fuente de energía en un aprendizaje de éxito. Esta se encuentra estrechamente vinculada con la comprensión emocional. Emociones y motivaciones deben ser entendidas como las cilindradas en cualquier aprendizaje humano. Por lo cual, el manejo de los docentes sobre el estado de ánimo de los estudiantes resulta determinante en todas las facetas y dinámicas educativas (Ibarrola, 2016). Pekrun (1992) y, especialmente, Goleman (1995) afirman que la inteligencia emocional está ligada a la motivación. Una persona es capaz de mejorar su propia motivación cuanto más inteligente es emocionalmente. Las emociones en la vida psicológica de un escolar poseen una alta influencia en las estrategias cognitivas $\mathrm{y}$, por consecuencia, en el acto educativo y en el rendimiento académico.

Desde el punto de vista fisiológico, la emoción es una reacción principalmente biológica (Reeve, 1994) que moviliza el cuerpo hacia una acción y objetivo específico. Por ejemplo, con la emoción de ira, la sangre fluye vigorosamente hacia las manos, el ritmo cardíaco se dispara, la adrenalina en nuestro cuerpo aumenta y ello desata una energía para realizar una acción vigorosa, propia de golpear algo o a alguien con facilidad. Estos cambios fisiológicos se deben a la intervención del sistema límbico, área específica del cerebro que se conforma, entre otras estructuras, por el hipocampo y la amígdala, las zonas encargadas de generar respuestas emocionales (Ibarrola, 2016).

Cuadro 1. Las funciones del sistema límbico con énfasis en regiones como el hipotálamo, la amígdala y la formación hipocámpica

\section{Responsabilidades del sistema límbico}

Funciones metabólicas

Funciones de supervivencia

Regulación térmica.

Funciones vegetatitvas.

Funciones reproductivas.
Emociones y sentimientos.

Ira y odio.

Miedo.

Pasión y tristeza.

Memoria.
Hipotálamo

Homeostasis del organimo en el desarrollo neuroendocrino y control autónomo.
Amígdala

Se encarga de las emociones y conductas.

Formación hipocámpica

Esta formación permite el desarrollo de la memoria. 
La emoción, por tanto, es capaz de originar componentes químicos en el cerebro que no solo se divulgan a través de la reacción axón-sinapsis-dendrita, sino que también se transmiten a distintas áreas del cuerpo. Dichos activos componentes son inducidos desde zonas como la médula, las glándulas suprarrenales, los riñones y las protuberancias anulares, las cuales conceden a los componentes químicos originados por las emociones intervenir sobre una gran parte de nuestros comportamientos (Ibarrola, 2016).

\section{Lenguaje}

Según Castellanos (2016), «el lenguaje nos permite gestionar nuestra propia inteligencia, tanto la inteligencia lingüística como la emocional» (p. 69). En esta visión, las palabras son los vehículos físicos de las emociones.

Otros autores, como Halliday, consideran que empleamos el lenguaje tanto para compartir información como para establecer y mantener relaciones sociales. Por tanto, el carácter de nuestro pensamiento depende cardinalmente de la manera con la que empleamos el lenguaje (Mercer, 2001).

Para nuestro campo es destacable señalar la teoría de Vygotsky (1978) sobre la diferencia entre la capacidad original y la capacidad potencial de un niño, denominada «zona de desarrollo próximo» (ZDP), la cual concebía que el diálogo, los factores situacionales y la actividad intramental influenciaba altamente en el desarrollo intelectual (Mercer, 2001). En definitiva, una buena instrucción podía influenciar (y mucho) en el proceso de interpensamiento y en el desarrollo del niño.

\subsection{Análisis de la alteración que el lenguaje ejerce sobre el cerebro}

El campo científico de la epigenética estudia cómo nuestros genes están regulados por el ambiente al que estamos expuestos, lo que produce una fuerte influencia en nuestra forma de vida, y donde una de las variables más destacadas es el ambiente lingüístico, tanto externo como interno al que nos exponemos. Una investigación realizada en el año 2010 demostró que el uso habitual de palabras negativas puede llegar a modificar nuestros genes. El investigador Keller y sus colaboradores analizaron los cerebros post morten de un número de personas que se suicidaron, concretamente estudiando la región cerebral vinculada con el uso de los significados del lenguaje, el área Wernicke, la cual se activa leyendo, oyendo una conversación con entendimiento o a través del habla o los pensamientos. El área Wernicke del cerebro de estas personas presentaba una menor cantidad de proteína BDNF (brain-derived neurotrophic factor) en comparación con personas sin ideas suicidas. 
La proteína BDNF es la neurotrofina que mayor expresión tiene en el cerebro y, de manera particular, en la corteza cerebral y en el hipocampo, áreas vitales para el aprendizaje y la memoria (Dusman et al., 1990). Los investigadores afirmaron que la causa de la disminución de esta proteína era la alteración de la estructura del gen que sintetizaba esta proteína debido a factores epigenéticos. En conclusión, los habituales pensamientos negativos y el uso continuado de un lenguaje hostil habían modificado el genoma (Castellanos, 2016) (véase figura 2).

Figura 2. Regiones cerebrales implicadas en el lenguaje y las emociones

\begin{tabular}{|c|c|c|}
\hline & Ínsula. & \\
\hline $\begin{array}{l}\text { Área de Broca. } \\
\text { Relacionada con la producción } \\
\text { del lenguaje y el procesamien- } \\
\text { to de la estructura sintáctica de } \\
\text { las oraciones. }\end{array}$ & $\begin{array}{l}\text { Área límbica que integra las respuestas peri- } \\
\text { féricas con áreas del neocórtex (corteza pre- } \\
\text { frontal). Interviene en el impacto de la intuición } \\
\text { en la toma de decisiones. }\end{array}$ & $\begin{array}{l}\text { Córtex parietal. } \\
\text { Integra la información sensorial para hacer una } \\
\text { representación compleja del entorno. Funda- } \\
\text { mental para los procesos de autoconsciencia, } \\
\text { juicios autorreferenciados y el sentido del yo. }\end{array}$ \\
\hline $\begin{array}{l}\text { Cíngulo. } \\
\text { Área límbica que asocia el des- } \\
\text { enlace de una acción con la } \\
\text { emoción y la motivación. Según } \\
\text { su valencia e intensidad, la ac- } \\
\text { ción y su contexto se registran } \\
\text { en memoria. }\end{array}$ & & $\begin{array}{l}\text { Area de Wernicke. } \\
\text { Relacionada con el recono- } \\
\text { cimiento de las palabras y el } \\
\text { procesamiento del significado. } \\
\text { Este puede incluir un compo- } \\
\text { nente emocional y motiva- } \\
\text { cional. }\end{array}$ \\
\hline $\begin{array}{l}\text { Corteza ventromedial. } \\
\text { Área orbitofrontal dedicada a la } \\
\text { percepción consciente de los } \\
\text { estímulos con valencia emocio- } \\
\text { nal. Se conecta con el ATV y la } \\
\text { amígdala, regulando la expre- } \\
\text { sión emocional. }\end{array}$ & & $\begin{array}{l}\text { Hipocampo. } \\
\text { Elabora y consolida la me- } \\
\text { moria durante el aprendizaje. } \\
\text { Cuando la información es re- } \\
\text { levante, pervive en la memoria } \\
\text { durante más tiempo. }\end{array}$ \\
\hline \multirow[t]{2}{*}{$\begin{array}{l}\text { Gracias a ella establecemos } \\
\text { juicios morales y la valoración } \\
\text { entre costes y beneficios ade- } \\
\text { cuados. }\end{array}$} & $\begin{array}{l}\text { ATV y núcleo accumbens. } \\
\text { Ambos forman un sistema dopaminérgi- } \\
\text { co del sistema de refuerzo o recompensa. } \\
\text { Regula funciones como la planificación, } \\
\text { la toma de decisiones, la motivación y el } \\
\text { refuerzo. }\end{array}$ & $\begin{array}{l}\text { Amígdala. } \\
\text { Evalúa el componente emocional de los estí- } \\
\text { mulos e inicia respuestas emocionales auto- } \\
\text { máticas. Cuando hacemos conscientes estos } \\
\text { componentes de la emoción surge el senti- } \\
\text { miento. }\end{array}$ \\
\hline & & Fuente: Castellanos (2016). \\
\hline
\end{tabular}

En 2009, el equipo de Martín Loeches, asesor científico de un centro de neurociencia cognitiva, estudió cómo las palabras de ánimo podían influir en nuestro cerebro, con técnicas de encefalografía y potenciales eventos-relacionados (PER), muy comunes en neurociencia cognitiva para identificar cambios en la actividad eléctrica de las neuronas al mostrar un estímulo (véase figura 3). Se colocaba a una persona ante una pantalla mientras se le daban indicaciones para realizar un ejercicio de atención con el fin de conocer si se veía influenciado por las palabras positivas que oía provenientes de una voz anónima. Y, efectivamente, un lenguaje positivo aumentaba la atención hacia el estímulo (Castellanos, 2016). 
Figura 3. Cómo afectan las palabras emocionales en nuestro cerebro

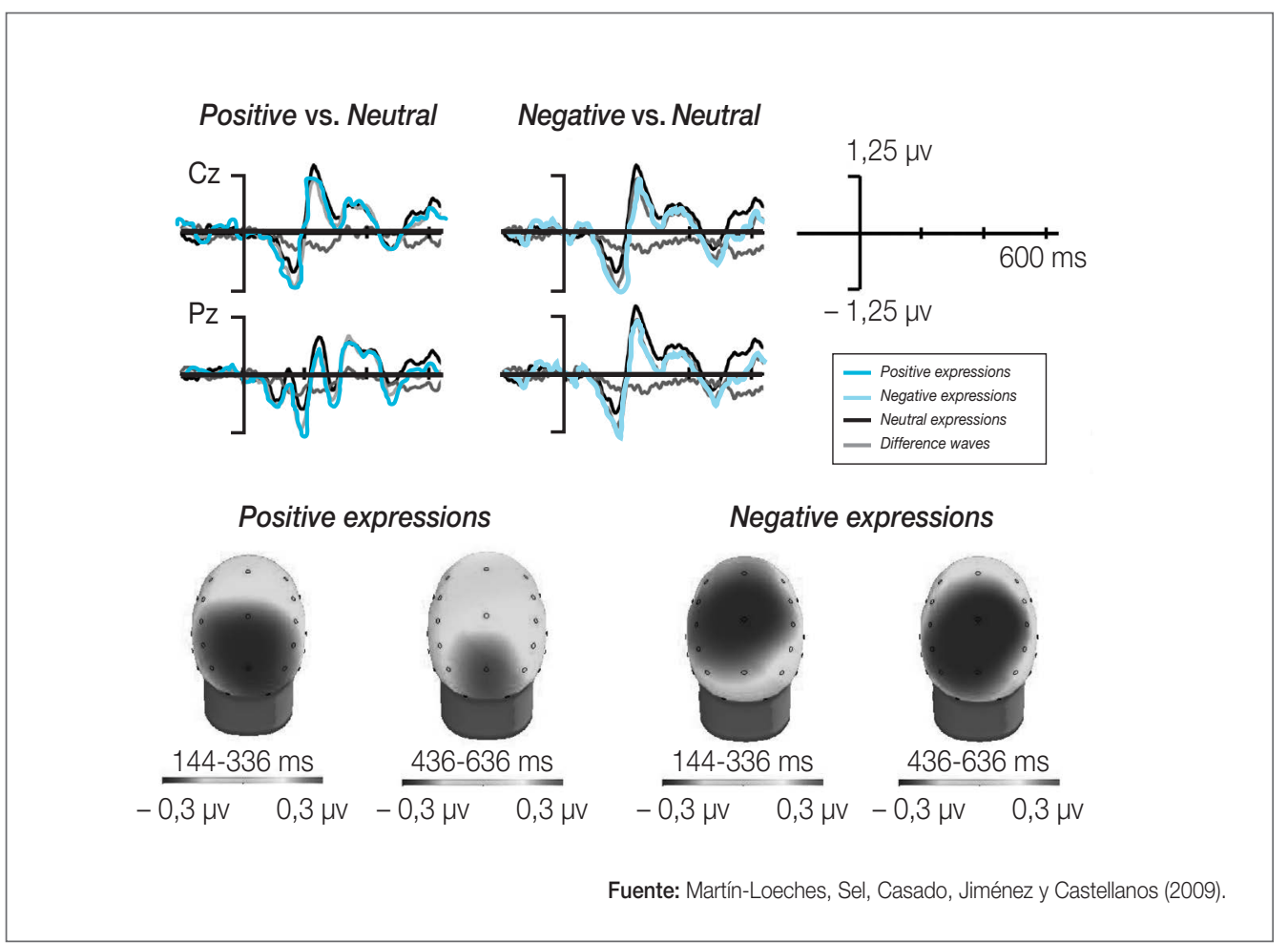

Otra investigación de la psiquiatra Alia-Klein, para comprobar el efecto de las palabras en el cerebro, reveló un aumento de la actividad de la amígdala, así como una mayor liberación de hormonas del estrés ante una palabra con una negativa carga emocional. Paralelamente, mostró que procesos cognitivos como la lógica, el razonamiento y la comunicación se veían gravemente perjudicados (Castellanos, 2016).

\subsection{La influencia del lenguaje en nuestro comportamiento}

Nuestro comportamiento se regula por cómo pensamos y cómo nos sentimos, de manera que las acciones que realizamos son manifestaciones de nuestra forma de pensar. Las palabras

Las acciones son manifestaciones de nuestra forma de pensar son capaces de construir circuitos, sinapsis constructivas en nuestro cerebro. Estas, junto con lo que pensamos, provocan reacciones dentro de la persona, produciendo cambios en el cuerpo (Forés y Ligioiz, 2009). 
Los mensajes celulares producidos por pensamientos o palabras emocionales agradables y de confianza aumentan la capacidad respiratoria y de oxigenación cerebral; provocan gestos y posturas calmosas, relajación muscular, apertura corporal de mayor seguridad, etc. De modo contrario, cuando una persona piensa
Las palabras y los pensamientos generan emociones diversas que producen un determinado estado de activación cerebral, que, por ende, se manifiesta en el comportamiento que tiene poca capacidad, recibe la liberación química correspondiente a ese pensamiento, la cual provoca hundir los hombros y encorvar la espalda. En cuanto a los cambios musculares, provoca un menor riego sanguíneo, disminuyendo la activación en el cerebro. La cierta liberación química continuada originará un circuito neuronal que provocará una tendencia de comportamiento habitual (Forés y Ligioiz, 2009).

En definitiva, las palabras y los pensamientos generan emociones diversas que producen un determinado estado de activación cerebral, que, por ende, se manifiesta en el comportamiento.

\section{El lenguaje positivo}

El lenguaje positivo es el hecho de poner inteligencia en el lenguaje. Significa entender, apreciar y usar las palabras que formulamos de una manera efectiva y beneficiosa para mejorar la comunicación, la relación con los demás, con uno mismo, y para la toma de decisiones (Castellanos, 2016).

El lenguaje positivo es el hecho de poner inteligencia en el lenguaje

Las palabras positivas son capaces de cambiar el rumbo de nuestras emociones. Palabras de contenido emocional positivo comunican estados emocionales positivos. Por ello, el lenguaje se configura como una pieza clave para elevar y mantener ese estado emocional y motivacional adecuado (Castellanos, 2017). Las palabras positivas y de ánimo favorecen a focalizar mejor los recursos cognitivos y ello contribuye a una mejor ejecución de cualquier actividad posterior a ese momento. Ciertas palabras, especialmente aquellas que tengan más significación sobre esa persona en particular, son capaces de activar una red extensa de áreas cerebrales en las que determinadas sustancias neuroquímicas funcionan como impulsores entre neuronas (Castellanos, 2016).

Las palabras positivas son capaces de cambiar el rumbo de nuestras emociones
El lenguaje positivo es capaz de modular funciones cognitivas importantísimas, como la atención, la memoria, la creatividad y la motivación, influyendo en la función ejecutiva y en nuestras conductas y comportamientos (Castellanos, 2016). 


\subsection{El lenguaje positivo en la enseñanza}

Se ha revisado el papel protagonista de las emociones como aquellas maestras altamente acondicionadoras e indispensables para que la disposición de los alumnos sea eficiente y las informaciones queden grabadas de forma intensa, mejorando así la capacidad de aprender. Por tanto, desde este planteamiento se aboga por un aprendizaje con diálogos cargados de emociones positivas para que las dinámicas educativas sean atractivas y motivadoras. «Si la educación no contiene un abanico poderoso de estimulación, difícilmente podremos saber nuestras facilidades y potencialidades» (Forés y Ligioiz, 2009, p. 72).

Una vez analizado que al cerebro le encantan y le seducen las palabras positivas, si se eleva su número, las funciones cognitivas funcionan mejor. Se mejoran los resultados por el condicionante de que el cerebro está trabajando con niveles más elevados de atención, memoria, creatividad y energía (Castellanos, 2017). Por tanto, debe ser el generador de un clima emocional positivo dentro del aula, tanto entre el binomio profesor-alumno como entre compañeros, suponiendo un facilitador para el proceso de enseñanza-aprendizaje, y, como resultado, para el aprendizaje de los alumnos.

\begin{abstract}
Una vez analizado que al cerebro le encantan y le seducen las palabras positivas, si se eleva su número, las funciones cognitivas funcionan mejor. Se mejoran los resultados por el condicionante de que el cerebro está trabajando con niveles más elevados de atención, memoria, creatividad y energía
\end{abstract}

El resultado de una convivencia escolar positiva produce efectos beneficiosos para el bienestar tanto personal como grupal. Según Ibarrola (2016), entre los citados efectos se encuentran correlaciones con la disminución de conductas disruptivas, absentismo escolar y la reducción de embarazos no deseados entre adolescentes.

\section{Las palabras positivas son la estimulación necesaria para la consecución de un eficaz y eficiente proceso de aprendizaje y para un mayor rendimiento en los resultados de los alumnos}

El amplio abanico de beneficios que implica promover un buen clima de convivencia social dentro de la comunidad educativa, y, en concreto, dentro de las aulas, supone una inversión mayor de tiempo y de recursos para proyectos y programas en la escuela que ayudará a alcanzar una de las grandes metas de la educación: mejores aprendizajes y desarrollo integral de los alumnos (Ibarrola, 2016).

Las palabras positivas son la estimulación necesaria para la consecución de un eficaz y eficiente proceso de aprendizaje y para un mayor rendimiento en los resultados de los alumnos (Castellanos, 2017; Forés y Ligioiz, 2009). 


\title{
5.2. El papel del profesor
}

Es una verdad axiomática que para que un enseñante enseñe y un educando aprenda han de emplear el diálogo y desarrollar un espacio compartido de comunicación (Mercer, 2001). Para Ferrés (2008):

\begin{abstract}
Si ser un buen educador comporta ser un buen comunicador, y si ser un buen comunicador implica capacidad de sintonía, el buen educador deberá tener capacidad de seducción, en el sentido de tener empatía con los deseos del interlocutor [...] solo se puede educar si se es capaz de seducir. Solo se puede sacar algo del interior si se es capaz de penetrar en él (pp. 48 y 49).
\end{abstract}

Un docente no es un simple instructor o facilitador de información, sino el creador de conocimientos potenciales en unos estudiantes que necesitan de un rol compartido, activo, cooperativo y reflexivo en la consecución de su propia comprensión (Mercer, 2001). La participación e implicación del alumnado en el proceso de aprendizaje le ayudará a grabar y a recordar, y los vínculos afectivos, a creer y a hacer (Forés y Ligioiz, 2009).

Los profesores deben ser conscientes de las técnicas de diálogo que emplean y, sobre todo, de la finalidad con que las emplean (Mercer, 2001). El lenguaje positivo puede ejercer un efecto transformador; para ello, cuanto mejor se conozcan los intereses, los objetivos y los puntos de vista de los estudiantes, mejor será la elección de las palabras que produzcan ese efecto que puede resultar determinante en el éxito o en el fracaso académico.
Cuanto mejor se conozcan los intereses, los objetivos y los puntos de vista de los estudiantes, mejor será la elección de las palabras que produzcan ese efecto que puede resultar determinante en el éxito o en el fracaso académico

Son varias las investigaciones que demuestran que los juicios y las jerarquías afectan en el rendimiento escolar de los alumnos; es decir, las ideas y los juicios que emite un profesor sobre el desempeño de un alumno suponen un factor determinante para que este alcance el éxito académico (Brophy y Good, 1974; Persell, 1977; Rosenthal, 1976; Smith, 1980).

\subsection{La influencia del lenguaje positivo en los alumnos}

Goleman y Boyatzis (2010) -el primero, mundialmente conocido por su teoría sobre la inteligencia emocional, y el segundo, investigador del liderazgo emocional- coinciden en que a las personas se les puede hacer sentir que son parte de algo importante. Para ellos, el motor emocional que puede producir esto es la capacidad de hablar de los sueños, de la construcción de metas positivas, pues estas activan los centros cerebrales. Se deduce 
que el calibre en cuanto al tipo de lenguaje, y, por ende, de pensamientos que un estudiante ejecute, puede determinar su comportamiento y, como consecuencia, que su aprendizaje se dirija a un camino de potencial éxito.

Por otro lado, publicaciones como la de Paul Piff en 2015, profesor de psicología y comportamiento social de la Universidad de California, en Irvine, o como la de la psicóloga estadounidense Francine Russo en 2016, ambas en la revista Mente y Cerebro, hablan de los beneficios del sentimiento de admiración (Castellanos, 2017). Los docentes influyen de una manera directa en los esquemas conductuales de los alumnos, siendo modelos de referencia, por lo que el docente, utilizando un lenguaje cercano, motivador, de confianza, de logros y retos ilusionantes, puede posibilitar estos beneficios.

En la labor docente, el lenguaje positivo es la herramienta para mejorar las relaciones, disminuir el miedo, las presiones y el estrés, manejar conflictos y aumentar la confianza y seguridad; en definitiva, para mejorar el clima de aprendizaje. La positividad en el lenguaje del docente genera mayor atención, memoria y creatividad (Fernández-Abascal, 2009). De este modo, los profesores se convierten en esti-

En la labor docente, el lenguaje positivo es la herramienta para mejorar las relaciones, disminuir el miedo, las presiones y el estrés, manejar conflictos y aumentar la confianza y seguridad; en definitiva, para mejorar el clima de aprendizaje muladores contagiosos de una actitud positiva. Cambios emocionales y anímicos pequeños, continuados, pero significativos, suponen en la fisiología nerviosa una modificación de la conducta social.

\subsection{A la búsqueda de metodologías apropiadas}

Para una escuela de éxito que proporcione aprendizajes de calidad es necesario la reflexión sobre las estrategias y las condiciones organizativas y metodológicas que se van a emplear. Resulta crucial que las aulas dispongan de una organización flexible y democrática, donde se apoyen los proyectos e iniciativas de sus miembros, se suscite la ayuda, el trabajo cooperativo, y donde se construya un clima de relaciones positivas y motivadoras (Palomera, 2017). Para ello, han de emplearse aquellas metodologías que permitan que los estudiantes se desarrollen y muestren su máximo potencial.

Desde esta visión, metodologías como el trabajo cooperativo, aprendizaje-servicio, por proyectos o basado en juegos suponen un mayor uso del lenguaje y del funcionamiento y desarrollo cognitivo en los alumnos. Estas formas de trabajo producen un mayor entrenamiento cognitivo y un mayor protagonismo de las relaciones. Se trabaja en un contexto en el que el cerebro funciona de manera natural hacia retos conjuntos y se unen las fortalezas que caracterizan a cada alumno para la consecución de un objetivo común y superior. 
En definitiva, se considera que todas estas metodologías originan una espiral positiva de clima motivador y de confianza en el grupo (Palomera, 2017).

La idea es apostar por una educación lingüístico-emocional, clave para un proceso vital de aprendizaje. Los docentes tienen la llave maestra para educar las habilidades emocionales a través del lenguaje y sus métodos, potenciando, a través del lenguaje positivo, las emociones positivas, y viceversa; para, además, aprovechar su efecto de contagio con la finalidad de favorecer los procesos de enseñanza.

\section{La idea es apostar por una educación lingüístico-emocional, clave para un proceso vital de aprendizaje. Los docentes tienen la llave maestra para educar las habilidades emocionales a través del lenguaje y sus métodos}

En conclusión, «necesitamos construir espacios educativos que hagan crecer las fortalezas individuales del alumnado para su crecimiento personal y social», y, para que esto suceda, la escuela debe ser «un centro dinamizador que trascienda su contexto y se extienda a la familia y a la sociedad» (Fernández-Berrocal y Extremera, 2009, p. 104).

\section{Conclusiones}

Los conocimientos actuales sobre la mente humana, descubiertos gracias a los avances de la neurociencia, han provocado una revolución en múltiples áreas de conocimiento. En educación, esta rama de la ciencia resulta crucial para el entendimiento de qué factores externos afectan a nuestro cerebro y sistema nervioso, para así comprender las bases biológicas y fisiológicas del comportamiento de los estudiantes (Squire, 2013).

Aunque dicho ámbito de estudio resulta relativamente novedoso, sus deliberaciones han revolucionado la forma de entender el funcionamiento del cerebro. La acción de aunar neurociencia y educación ha dado lugar a lo que se conoce como «neuroeducación», la cual, gracias a los avances tecnológicos, ha posibilitado el estudio interdisciplinar de mente, cerebro y educación por parte de investigadores, profesores y estudiantes (Battro, Fischer y Léna, 2008). Emoción y cognición son procesos que van de la mano y, entendiendo la emoción como un elemento trascendental en el aprendizaje, el lenguaje positivo se encarna como el medio principal para su influencia.

La neuroeducación manifiesta de manera rotunda la idoneidad de incluir la emoción en el proceso de enseñanza-aprendizaje. El docente no debe ser un mero transmisor de información, 
sino un creador de conocimientos y experiencias enriquecedoras con la finalidad de suscitar curiosidad y motivación hacia el aprendizaje (Ferrés, 2014). Para Ferrés y Masanet (2017):

Potenciar la dimensión emocional en la comunicación educativa comporta diseñar estrategias en las que se atienda la multiplicidad de intereses diversos que mueven a unos estudiantes y a otros. En definitiva, la habilidad más preciada de un comunicador educativo es la capacidad de movilización, implicación e interacción (p. 60).

Por ello, un profesor tiene la capacidad, a través de la educación lingüístico-emocional, de favorecer los procesos de enseñanza-aprendizaje, y la mejor herramienta para potenciar dicho acto es el lenguaje positivo (Castellanos, 2017). Este ofrece un mejor rendimiento cognitivo que potencia los procesos de atención, memoria, motivación y creatividad, claves en cualquier aprendizaje. El lenguaje positivo, por
Un profesor tiene la capacidad, a través de la educación lingüístico- emocional, de favorecer los procesos de enseñanza-aprendizaje, y la mejor herramienta para potenciar dicho acto es el lenguaje positivo tanto, crea el ambiente adecuado para el desarrollo cognitivo del alumno y de las relaciones, así como de las dinámicas, favoreciendo el ánimo con el que se educa y aprende.

Se ha revisado que las personas que se sienten bien tienen un pensamiento óptimo para las relaciones sociales, influyendo en sus conductas en el aula y en su estilo de vida en general (Castellanos, 2016). Las aplicaciones prácticas del lenguaje positivo son extrapolables a casi todos los ámbitos de la vida, ya que las palabras están siempre presentes allá donde vamos y pueden ser definitorias de éxito, salud y felicidad (Ibarrola, 2016).

Por esto, los docentes deben ser conscientes del valor de las palabras y sus efectos, así como sus potencialidades (Castellanos, 2017). El sistema educativo rara vez enseña las distintas formas de emplear el lenguaje de manera eficaz y, menos aún, como herramienta para potenciar el aprendizaje (Mercer, 2001). Es fundamental, por tanto, que los alumnos conozcan las potencialidades del lenguaje y lo utilicen para mejorar sus fortalezas y que estas ejerzan de vehículo para el éxito personal y laboral (Jiménez, Alvarado y Puente, 2013).

Tras lo revisado, se confirma que el tipo de lenguaje que los docentes emplean con sus discentes desempeña un papel protagónico y crucial para el desarrollo del rendimiento de los estudiantes. El objetivo principal de cualquier docente debería ser siempre capacitar a sus estudiantes para que desplieguen su máximo potencial. Asimismo, el tipo de lenguaje influye en la conducta, y su uso crea un ecosistema positivo que mejora las relaciones, tanto con
El tipo de lenguaje que los docentes emplean con sus discentes desempeña un papel protagónico y crucial para el desarrollo del rendimiento de los estudiantes. El objetivo principal de cualquier docente debería ser siempre capacitar a sus estudiantes para que desplieguen su máximo potencial 
uno mismo como con los demás, de manera que todos los protagonistas involucrados en el proceso de enseñanza-aprendizaje se benefician, alcanzando estados óptimos de aprendizaje (Castellanos, 2017). Se ratifica que el lenguaje positivo estimula procesos cognitivos como la atención, la memoria, la motivación y la creatividad, mejorando y amplificando el aprendizaje de los educandos.

Tras el estudio de esta investigación se puede afirmar que el uso de un lenguaje positivo por parte del docente mejora el proceso de enseñanza-aprendizaje y, por tanto, el rendimiento académico de los alumnos.

\section{Referencias bibliográficas}

Battro, A., Fischer, K. y Léna, P. (2008). The Educated Brain: Essays in Neuroeducation. Nueva York, EE. UU.: Cambridge University Press.

Böttger, H. (2016). Neurodidaktik des frühen Sprachlernens: Wo die Sprache zuhause ist. Stuttgart, Alemania: Deutsche Bibliothek.

Brophy, J. E y Good, T. (1974). Teachers' communication of differential expectations for children's classroom performance: some behavioral data. Journal of Educational Psychology, 61, 365-374.

Cabrera, J. D. (2003). Discurso docente en el aula. Estudios Pedagógicos, 29, 7-26.

Castellanos, L. (2016). La ciencia del lenguaje positivo. Barcelona, España: Paidós.

Castellanos, L. (2017). Educar en lenguaje positivo. Barcelona, España: Paidós.

Damasio, A. (1994). El error de Descartes. Barcelona, España: Crítica.

Damasio, A. (2001). La sensación de lo que ocurre: cuerpo y emoción en la construcción de la conciencia. Madrid, España: Debate.

Damasio, A. (2005). En busca de Spinoza: neurobiología de la emoción y los sentimientos. Barcelona, España: Crítica.
Delors, J. (1996). La educación encierra un tesoro. Madrid, España: Santillana.

Delval, J. (1996). Los fines de la educación. Madrid, España: Siglo XXI Editores.

Dustman, R. E., Emmerson, R. Y., Ruhling, R. O., Shearer, D. E., Steinhaus, L. A., Johnson, S. C., ... y Shigeoka, J. W. (1990). Age and fitness effects on EEG, ERPs, visual sensitivity and cognition. Neurobiology of Aging, 11, 193-200.

Echeverría, R. (2003). Ontología del lenguaje. Santiago, Chile: Comunicaciones Noroeste.

Fernández-Abascal, E. G. (2009). Emociones positivas. Madrid, España: Pirámide.

Fernández-Berrocal, P. y Extremera, N. (2009). La inteligencia emocional y el estudio de la felicidad. Revista Interuniversitaria de Formación del Profesorado, 66, 85-108.

Ferrés i Prats, J. (2008). La educación como industria del deseo: un nuevo estilo comunicativo. Barcelona, España: Gedisa Editorial.

Ferrés i Prats, J. (2014). Las pantallas y el cerebro emocional. Barcelona, España: Gedisa.

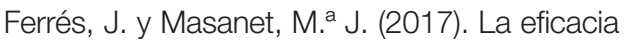
comunicativa en la educación: potenciando las emociones y el relato. Comunicar, 52, 51-60. 
Forés, A. y Ligioiz, M. (2009). Descubrir la neurodidáctica: aprender desde, en y para la vida. Barcelona, España: Editorial UOC.

Forés, A., Gamo, R., Guillén, J., Hernández, T., Ligioiz, M., Pardo, F. y Trinidad, C. (2015). Neuromitos en educación: el aprendizaje desde la neurociencia. Barcelona, España: Plataforma Actual.

Fundación BBVA. (2018). La tasa de abandono escolar en España es un $80 \%$ superior a la media europea, pese a que siete autonomías ya han conseguido reducirla al objetivo marcado para 2020. Esenciales, 23. Recuperado de <https://www.fbbva.es/noticias/la-tasaabandono-escolar-temprano-espana-80superior-la-media-europea-pese-sieteautonomias-ya-conseguido-reducirla-alobjetivo-marcado-2020/> (consultado el 12 de marzo de 2018).

Goleman, D. (1995). Inteligencia emocional. Barcelona, España: Kairós.

Goleman, D. y Boyatzis, R. (2010). El líder resonante crea más. Barcelona, España: Debolsillo.

Greco, C., Morelato, G. e Ison, M. (2006). Emociones positivas: una herramienta psicológica para promocionar el proceso de resiliencia infantil. Psicodebate: Psicología, Cultura y Sociedad, 7, 81-94.

Guillén, J. (2016). Las claves de la neuroeducación. Niuco. Recuperado de <http:// www.niuco.es/2016/03/03/las-claves-dela-neuroeducacion/> (consultado el 3 de mayo de 2018).

Hart, L. (1983). Human Brain \& Human Learning. Nueva York, EE. UU.: Longman.

Ibarrola, I. (2016). Aprendizaje emocionante: neurociencia para el aula. Madrid, España: Editorial SM.

Isen, A. M. (1987). Positive affect, cognitive processes, and social behavior. En L. Berkowitz
(Ed.), Advances in Experimental Social Psychology (Vol. 20, pp. 203-253). Academic Press.

Jiménez, V., Alvarado, J. M. y Puente, A (2013). Una aproximación al trabajo socia desde la óptica de la psicología positiva (virtudes y fortalezas). Cuadernos de Trabajo Social, 26(2), 397-407.

L'Ecuyer, C. (2012). Educar en el asombro. Barcelona, España: Plataforma Editorial.

Marina, J. (2012). Neurociencia y educación. Participación Educativa. Revista del Consejo Escolar del Estado, 1, 7-14. Recuperado de $<$ https://sede.educacion.gob. es/publiventa/descarga.action?f_codigo_ agc $=15795$ > (consultado el 26 de febrero de 2018).

Martín-Loeches, M., Sel, A., Casado P., Jiménez, L. y Castellanos, L. (2009). Encouraging expressions affect the brain and alter visual attention. PLoS One, 4(6).

Maturana, H. (2009). La realidad: ¿objetiva o construida? I. Fundamentos biológicos de la realidad. Barcelona, España: Anthropos.

Mayer, R. E. (2003). Learning and Instruction. Nueva Jersey, EE. UU.: Merrill/Prentice Hall.

McEwen, B. S. y Sapolsky, R. M. (1995). Stress and cognitive function. Current Opinion in Neurobiology, 5, 205-216.

Mercer. N. (2001). Palabras y mentes: cómo usamos el lenguaje para pensar juntos. Barcelona, España: Paidós.

Mora, F. (2013). Neuroeducación: lo que nos enseña el cerebro. Madrid, España: Alianza Editorial.

Mora, F. y Sanguinetti, A. (2004). Diccionario de neurociencias. Madrid, España: Alianza Editorial.

Morín, E. (1992). El método IV. Las ideas: su hábitat, su vida, sus costumbres, su organización. Madrid, España: Cátedra. 
Palomera, R. (2009). Educando para la felicidad. En E. Fernández-Abascal (Coord.), Emociones positivas (pp. 247-274). Madrid, España: Pirámide.

Pekrun, R. (1992). The impact of emotions on learning and achievement: towards a theory of cognitive/motivational mediators. Applied Psychology: An International Review, 41(4), 359-376.

Persell, C. (1977). Education and Inequality: The Roots and Results of Stratification in American Schools. Nueva York, EE. UU.: The Free Press.

Reeve, J. (1994). Motivación y emoción. Madrid, España: McGraw-Hill.

Rosenthal, R. (1976). Experimenter Effects in Behavioral Research. Nueva York, EE. UU.: Irvington.

Rosenthal, R. y Jacobson, L. (1980). Pygmalion en la escuela: expectativas del maestro y desarrollo intelectual del alumno. Madrid, España: Marova.

Rosenthal, R. y Rubin, D. (1978). Interpersonal expectancy effects: the first 345 studies. The Behavioral and Brain Sciences, 3, 377-415.

Saavedra, J., Díaz, W., Zúñiga, L., Navia, C. y Zamora, T. (2015). Correlación funcional del sistema límbico con la emoción, el aprendizaje y la memoria. Morfolia, 7(2), $29-44$.
Salovery, P. y Mayer, J. D. (1990). Emotional intelligence. Imagination, Cognition, and Personality, 9, 185-211.

Seligman, M. E. P., Ernst, R. M., Gillham, J., Reivich, K. y Linkins, M. (2009). Positive education: positive psychology and classroom interventions. Oxford Review of Education, 35(3), 203-311.

Smith, M. L. (1980). Teacher expectations. Evaluation in Education, 4, 53-55.

Squire, L. (2013). Fundamental neuroscience. Oxford, Reino Unido: Elsevier.

Sutton, R. E. y Wheatly, K. F. (2003). Teacher's emotions and teaching: a review of the literature and directions for future research. Educational Psychology Review, 15(4), 327-358.

Vygotsky, L. S. (1978). Mind in society: the development of higher psychological processes. Cambridge, Reino Unido: Harvard University Press.

Vygotsky, L. S. (1988). El desarrollo de los procesos psicológicos superiores. México: Editorial Crítica, Grupo Editorial Grijalbo.

Westling, M. (2002). A two level analysis of classroom climate in relation to social context, group composition and organization of special support. Learning Environments Research, 5, 253-274.

Zambrano Leal, A. (2001). La mirada del sujeto educable, la pedagogía y la cuestión del otro. Cali, Colombia: Editores-Impresores. 


\section{Magisterio de Educación Infantil}

Hoy en día los centros educativos tienen una imperiosa necesidad de disponer de personal especializado, capaz de hacer frente a las necesidades educativas de la etapa infantil, de acuerdo con los conocimientos ya logrados por las diversas ciencias que hoy se ocupan de los niños en los primeros años de su vida, así como de los logros relativos al desarrollo de la inteligencia, la emocionalidad y la formación de la personalidad temprana, resultantes de estudios recientes sobre el desenvolvimiento de la mente infantil.

\section{Magisterio de Educación Primaria}

Son objetivos de la educación primaria, entre otros: conocer y apreciar los valores y las normas de convivencia, aprender a obrar de acuerdo con ellas, prepararse para el ejercicio activo de la ciudadanía y respetar los derechos humanos, así como el pluralismo propio de una sociedad democrática. También, desarrollar hábitos de trabajo individual y de equipo, de esfuerzo y responsabilidad en el estudio, así como actividades de confianza en uno mismo, sentido crítico, iniciativa personal, curiosidad, interés y creatividad en el aprendizaje.

\section{Menciones en los grados de} Magisterio de Educación Infantil y de Magisterio de Educación

\section{Primaria}

Mención en Lengua Inglesa

Mención en Pedagogía Terapéutica

Mención en Audición y Lenguaje

Mención en Tecnología Educativa

Mención en Enseñanza de la Religión Católica

\section{Curso de adaptación al grado}

Este curso de adaptación al grado ofrece a los maestros diplomados en la Especialidad de Educación Infantil o Primaria la posibilidad de obtener formación en campos determinados dentro del ejercicio profesional docente en estas etapas, a través de las menciones cualificadoras mencionadas anteriormente.

El objetivo principal del plan de estudios de este curso de adaptación al grado es contribuir a la actualización de la formación de los maestros diplomados. La aplicación de las TIC a la educación y de líneas pedagógicas innovadoras, fruto de la investigación en educación, hacen necesaria la actualización de los conocimientos didácticos de los diplomados y la formación de los maestros en investigación e innovación.

Al finalizar el curso de adaptación se obtiene el título de grado en Magisterio de Educación Infantil o en Magisterio de Educación Primaria.

La docencia en la etapa de educación infantil o primaria es una profesión regulada. Los graduados en Magisterio de Educación Infantil o en Magisterio de Educación Primaria tienen como principal salida profesional el trabajo como profesores en estas etapas, tanto en centros públicos como concertados y privados.

Si bien otras salidas profesionales para estos títulos pueden ser:

- Participación en proyectos educativos de organismos e instituciones (centros culturales, museos, asociaciones, ONG, etc.).

- Centros de educación para adultos.

- Centros de ocio y tiempo libre.

- Participación en programas de extensión educativa (actividades extraescolares, actividades de apoyo, etc.).

- Diseño y elaboración de materiales didácticos.

- Participación en proyectos de atención a la infancia y familiar. 